\title{
PENGUKURAN PERFORMANSI RANTAI PASOK PADA INDUSTRI BATIK TIPE PRODUKSI MAKE-TO-STOCK DENGAN MENGGUNAKAN MODEL SCOR 11.0 DAN PEMBOBOTAN AHP (Studi Kasus Batik Gunawan Setiawan, Surakarta)
}

\author{
Taufiq Immawan ${ }^{1}$, Chandra Yuda Pratama ${ }^{2}$ \\ Jurusan Teknik Industri Fakultas Teknologi Industri Universitas Islam Indonesia, ${ }^{1,2}$ \\ Jl. Kaliurang KM. 14,5 Sleman, Yogyakarta \\ E-mail:immawan16@gmail.com ${ }^{1}$,chandrayuda14@gmail.com ${ }^{2}$
}

\begin{abstract}
Batik is Indonesia's cultural heritage has been recognized through this UNESCO.Hal impact increased competition among industry batik.Salah an effort in order to win the competition is to determine the performance of supply chain industry batik.Pada this study measured the performance of the supply chain of industrial production type Make-batik toStock, case studies Batik Gunawan Setiawan using the SCOR model and weighting 11.0 AHP.Tujuan this study was to determine the performance of supply chain at Batik Gunawan Setiawan. The results of this study, the measurement of each attribute using the SCOR model 11.0 to 98.17\% batik Reliability, Responsiveness 64.40 today, 14:39 today Agility, Cost Rp. 185 173. 537, -, and Asset Management 20:15 today. The measurement results batik 97.65\% Reliability, Responsiveness 40.78 days, 14.70 days Agility, Cost Rp. 273292 491, -, and Asset Management 18:04 today. And the measurement results batik combined 97.60\% Reliability, Responsiveness 60.19 days, 17.61 days Agility, Cost Rp. 271219 750, -, and Asset Management 21:17 today. The average results of measurement are included in the category of Average. Large attribute weights using AHP ie Reliability 0079, responsivenes 0194, 0035 Agility, Cost 0689, and 0003 Asset Management. Weights tge ie Cost. The results of the industry supply chain performance measures Batik Gunawan Setiawan ie 68.79\% included in the category of Average. Recommendations are given is to eliminate the patterning process of batik as an Innapriorate processing. Reducing the waiting time from the process of negotiation and supplier selection colouring. Doing to improve the performance of the procurement of raw materials.
\end{abstract}

Keywords: Supply Chain, Performance Measurement, Industry Batik, Make-To-Stock, SCOR, AHP.

\section{PENDAHULUAN}

Batik dinilai sebagai sebuah karya budaya yang memiliki nilai ekonomi tinggi, karena menjadi sumber hidup bagi para pengrajinnya, membuka lapangan usaha, menambah devisa negara, dan mendukung kepariwisataan yang sangat potensial (Sumintarsih, 2009). Batik tidak terlepas dari proses manufaktur, De Garmo et al. (1997), mendefinisikan manufaktur sebagai istilah ekonomi untuk membuat barang dan jasa yang tersedia untuk memuaskan pelanggan.
Manufaktur sendiri erat kaitannya dengan proses pengadaan yaitu hubungan dengan pemasok dan distribusi pengiriman produk kepada konsumen, jaringan ini disebut sebagai rantai pasok (Supply Chain). Menurut Pujawan (2005), rantai pasok merupakan pengelolaan hubungan antar jaringan perusahaan yang bekerjasama untuk meciptakan dan menghantarkan produk kepada tangan pemakai akhir secara bersama - sama.

Untuk memiliki nilai rantai pasok yang baik maka perlu dilakukan pengelolaan rantai pasok yang disebut sebagai Supply Chain 
Management (SCM). Supply Chain Management (SCM) didefinisikan sebagai pengelolaan pertukaran bahan dan informasi dalam proses logistik yang membentang dari pembelian bahan baku untuk pengiriman produk akhir ke konsumen akhir, sehingga menghubungkan beberapa perusahaan (Cooper et al., 1997). Salah satu cara untuk melakukan pengelolaan rantai pasok yaitu dengan cara melakukan pengukuran perfromansi rantai pasok. Salah satu model yang dapat digunakan untuk melakukan pengukuran peformansi rantai pasok yaitu model SCOR. Model SCOR dikembangkan oleh Supply Chain Council (SSC) dimana pengembangannya yang terbaru yaitu dikenal sebagai SCOR versi 11.0.Menurut Georgise \& Thoben (2013), menyatakan bahwa SCOR merupakan sebuah proses referensi model yang berfungsi sebagai alat untuk mendiagnosa Supply chain management (SCM). Dengan menggunakan model SCOR maka dapat dilakukan pengukuran setiap aktivitas - aktivitas dalam proses bisnis perusahaan secara detail dari hulu ke hilir. SCOR menyediakan perusahaan dengan alat dasar pemodelan proses, database pasokan yang luas, dan panduan tentang bagaimana mengukur operasi rantai pasok (Persson, 2011).Industri batik sendiri tidak terlepas dari proses rantai pasoknya.

Pada tanggal 2 oktober 2009 batik telah diakui oleh UNESCO sebagai karya bangsa Indonesia dalam World Heritage, hal ini memberikan dampak positif pada industri batik khususnya, yaitu meningkatnya permintaan pasar, namun disisi lain persaingan menjadi lebih ketat. Salah satu industri batik yang terlibat dalam persaingan yaitu Batik Gunawan setiawan.Pengakuan dunia atas batik Indonesia membawa konsekuensi untuk terus memilikinya, menjaganya, dan melestarikannya (Sumintarsih, 2009). Apabila tidak dilakukan pengukuran performansi rantai pasok dan perusahaan tidak memiliki referensi maka industri batik, khususnya Batik Gunawan Setiawan akan kalah dalam persaingan global. Namun di Indonesia ini perhatian terhadap industri batik sendiri masih sangat kurang ini terlihat dari beberapa tahun terakhir penelitian-penelitian mengenai pengukuran performansi rantai pasok industri batik sangat jarang.Peneliti lebih fokus pada industri otomotif, oil, dan makanan.

Pada saat ini Batik Gunawan Setiawan dihadapkan oleh berbagai permasalahan dalam menjalankan usahanya.Salah satunya yaitu tingginya tingkat ketidakpastian dalam permintaan pasar. Seperti diketahui permintaan pasar dalam periode tertentu selalu berubah - ubah. Selain itu hubungan antara pemasok yang menunjang bahanbaku kepada perusahaan masih ditemukan permasalahan, seperti bahan baku yang cacat dan lama waktu pengiriman bahan kepada perusahaan. Dari sisi internal perusahaan sendiri, masih ditemukannya produk-produk cacat yang dapat merugikan perusahaan.Oleh karena itu dalam penelitian ini dilakukan pengukuran performansi rantai pasok industri batik dengan studi kasus yaitu Batik Gunawan setiawan dengan menggunakan model SCOR 11.0 dan pembobotan AHP. Dimana model SCOR digunakan untuk mengukur masing-masing atribut dalam SCOR yaitu Reliability, Responsiveness, Agility, Cost dan Asset management dengan mengukur pada masing -masing jenis produk yang dihasilkan, dalam hal ini yaitu batik tulis, cap, dan kombinasi. Dengan menggunakan model SCOR maka dapat dilakukan pengukuran terhadap setiap aktivitas - aktivitas dalam proses bisnis Batik Gunawan Setiawan secara detail sehingga dapat menekan ketidakpastian dalam hubungan jaringan antar perusahaan yaitu dari pemasok sampai ke konsumen akhir.AHP digunakan untuk menghitung bobot atau tingkat kepentingan dari masing masing atribut SCOR. Pembandingan masing - masing atribut meningkatkan kemungkinan untuk meningkatkan nilai terlemah antar atribut. Dilakukannya pembobotan dikarenakan masing - masing sistem dalam berbagai industri tentunya berbeda - beda 
maka tingkat kepentingan antar masing masing atribut rantai pasok tentunya berbeda - beda. Hal ini didukung oleh penelitian yang dilakukan oleh Xia et al. (2007), yang menyatakan bahwa untuk strategi yang berbeda tingkat kepentingan dari atribut rantai pasok akan berbeda pula. Telah dilakukan penggabungan antara model SCOR dengan AHP oleh Huan et al. (2004), penelitian tersebut mengajukan penggunaan AHP sebagai alat bantu hitung dalam proses pengukuran performa SCM sebuah perusahaan. Alasan digunakan AHP sebagai alat bantu dalam SCOR adalah karena perusahaan membutuhkan sebuah metode yang dapat mengkualifikasikan suatu tujuan tertentu. Penelitian ini bertujuan untuk mengetahui nilai masing - masing atribut yang berhubungan dengan performansi rantai pasok pada Batik Gunawan Setiawan. Lalu untuk mengetahui tingkat kepentingan atau bobot antar masing - masing atribut tersebut. Untuk mengetahui hasil pengukuran performansi rantai pasok pada Batik Gunawan Setiawan. Oleh karena itu diharapkan dengan dilakukan penelitian ini dapat membantu perusahaan yaitu Batik Gunawan Setiawan dalam menghadapi persaingan dan dapat melestarikan batik, selain itu juga dapat dijadikan referensi oleh perusahaan dan penelitian selanjutnya dalam peningkatan performansi rantai pasok pada industri batik.

\section{KAJIAN LITERATUR}

\subsection{Batik}

Menurut Djumena (1990), seni batik adalah salah satu kesenian khas Indonesia yang telah ada sejak berabad - abad lamanya hidup dan berkembang, sehingga merupakan salah satu bukti peninggalan sejarah budaya bangsa Indonesia. Menurut Sumintarsih (2009), batik merupakan kerya budaya bangsa Indonesia yang merefleksikan sebuah produk seni yang memilik estetika dan filososfi yang tinggi. Menurut Sarmini (2009), batik merupakan keutuhan karya mulai dari proses pembuatan, ornamentasinya, hingga apresiasi dan etika mengenakannya.

Di Indonesia, batik dipercaya sudah ada semenjak zaman Majapahit, oleh karena itu batik di Indonesia sangat erat hubungannya dengan kerajaan Majapahit dan penyebaran agama Islam di Jawa. Dalam beberapa catatan, pengembangan batik banyak dilakukan pada masa-masa kerajaan Mataram, kemudian pada masa kerajaan Solo dan Yogyakarta (Dedi, 2009).Jadi kesenian batik sudah dikenal sejak zaman kerajaan Majapahit dan terus berkembang pada kerajaan dan Raja berikutnya. Kemudian pada abad ke-18 atau abad ke-19 batik mulai meluas ke wilayah Indonesia. Batik Solo terkenal dengan corak dan pola tradisionalnya dalam proses batik tulis maupun batik cap. Bahan pewarnaannya menggunakan soga, dan polanya yang terkenal Sidomukti dan Sidoluhur. Sedangkan batik Yogyakarta terkenal sejak kerajaan Mataram I. Daerah pembatikan pertama adalah Plered.Pada awalnya batik dibuat dan dikenakan oleh keluarga raja, tetapi pada hari - hari berikutnya, rakyat sering melihat pakaian keluarga raja dan ditiru oleh rakyat.Akhirnya pembatikan meluas ke luar dari tembok keraton (Sumintarsih, 2009).

\subsection{Supply Chain Management (SCM)}

Menurut Pujawan \& Mahendrawathi (2010), Supply chain adalah jaringan perusahaan-perusahaan yang secara bersama - sama bekerja untuk menciptakan dan menghantarkan suatu produk ke tangan pemakai akhir. Ada tiga aliran yang harus dikelola didalam supply chain, yaitu yang pertama adalah aliran barang yang mengalir dari hulu (upstream) ke hilir (downstream), kedua adalah aliran uang dan ketiga adalah aliran informasi. Perusahaan - perusahaan tersebut biasanya pemasok, pabrik, distributor, toko atau ritel dan perusahaanperusahaan pendukung seperti perusahaan jasa logistik. Sebuah produk akan sampai ke tangan pemakai akhir, setelah setidaknya mengalami beberapa proses dari pencarian 
bahan baku, proses produksi dan proses distribusi atau transportasi.

Menurut Heizer \& Render (2005), definisi manajemen rantai pasokan (SCM) adalah pengintegrasian aktivitas pengadaan bahan dan pelayanan, pengubahan menjadi barang setengah jadi, dan produk akhir, serta pengiriman ke pelanggan. Hanna \& Newman (2001), mendefinisikan SCM sebagai konfigurasi, koordinasi, dan peningkatan dari sebuah gabungan rangkaian operasi yang saling terkait.Menurut Russell \& Taylor (2003), SCM mengatur aliran barang dan jasa, serta informasi yang diteruskan ke pesanan untuk mencapai tingkat keselarasan atau sinkronisasi dalam memenuhi kebutuhan pelanggan.

\subsection{Pengukuran Performansi}

\subsubsection{SCOR (Supply Chain Operation Reference) 11.0}

Menurut Paul (2014), model Supply Chain Operation Reference (SCOR) adalah sebuah bahasa rantai suplai, yang dapat digunakan dalam berbagai konteks untuk merancang, mendeskripsikan, mengonfigurasi dan mengonsfigurasi ulang berbagai jenis aktivitas komersial / bisnis. Kelebihan titik model SCOR sebagai model proses referensi adalah kemampuan untuk mengintegrasikan proses bisnis rekayasa ulang, Benchmarking dan Best PracticesAnalysis dalam kerangka rantai pasokan. Model SCOR dikembangkan untuk menerapkan dan memperbaiki keadaan rantai pasok.SCOR mampu memberikan metodologi komprehensif untuk meningkatkan kinerja SCM.SCOR adalah salah satu kerangka kerja yang fleksibel dan mampu mendukung perusahaan untuk memperbaiki sistem rantai pasok baik secara internal maupun eksternal. SCOR memiliki fungsi untuk mengevaluasi tujuan, efektifitas rekayasa ulang, kinerja, kuantifikasi, pengujian, dan perencanaan masa depan serta proses tertentu dalam rantai pasokan.

Model SCOR memiliki beberapa level dalam hirarki prosesnya yaitu dapat dilihat pada gambar 1 Level 1 mendefinisikan ruang lingkup dan isi dari proses manajemen inti untuk daerah keputusan. Sebagai contoh, proses Rencana SCOR didefinisikan sebagai proses-proses yang menyeimbangkan permintaan agregat dan penawaran untuk mengembangkan tindakan yang terbaik memenuhi persyaratan sumber, produksi, dan pengiriman. Level 2 menggambarkan karakteristik yang terkait dengan jenis proses berikut dikerahkan dalam proses inti yaitu perencanaan, pelaksanaan dan memungkinkan. Misalnya, mitra rantai pasokan memerlukan proses untuk perencanaan rantai pasokan secara keseluruhan, serta proses perencanaan untuk sumber pendukung, membuat, menyampaikan, dan keputusan kembali. Karakteristik terkait dengan proses perencanaan yang efektif mencakup keseimbangan antara permintaan dan penawaran dan horizon perencanaan yang konsisten. Model SCOR juga berisi Level 2 kategori proses didefinisikan oleh hubungan antara proses manajemen inti dan jenis proses. Level 3 memberikan informasi elemen proses rinci untuk setiap tingkat 2 kategori proses. Input, output, deskripsi dan aliran dasar elemen proses yang ditangkap pada tingkat ini dari model SCOR (Lockamy et al., 2004).

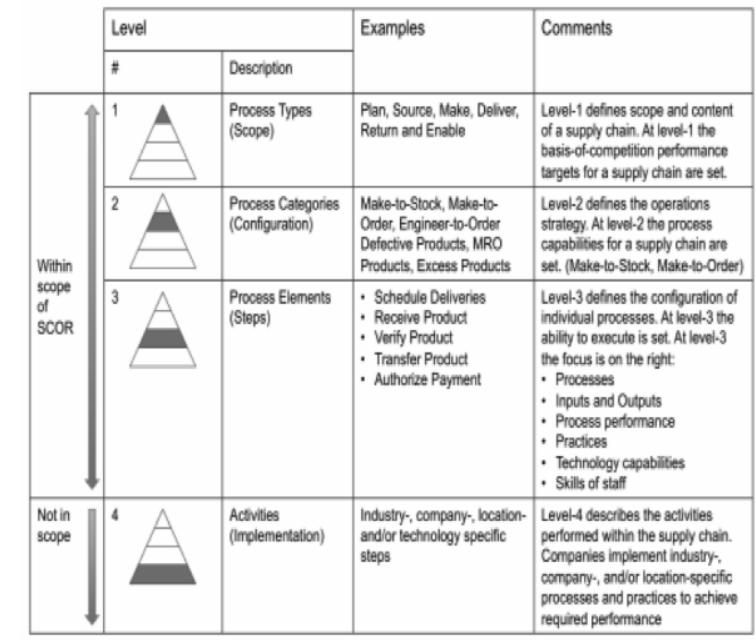

Gambar 1 Model Hirarki Proses SCOR. (Sumber : SCOR 11.0)

Model pembangunan SCOR didasarkan pada prinsip - prinsip dan pedoman yang 
disediakan oleh Supply Chain Council (SCC) sebagai pengembang SCOR. SCOR 11.0 dimulai dengan Level 1 yang menggambarkan proses SCOR yang terbagi dalam Plan, Source, Make, Deliver, Return, dan Enable. Kemudian, Level 2 memecah konfigurasi proses yang tergantung pada proses bisnis yang diterapkan oleh perusahaan. Level 3 menguraikan unsurunsur proses yang melibatkan Reliability, Responsiveness, Agility, Cost dan Assets management.

Adapun kategori dalam pengukuran performansi dikelompokan berdasarkan tingkat presentasi dari masing-masing hasil pengukuran. Berikut tabel sistem monitoring dan indikator performansi dalam rantai pasok seperti di bawah ini :

Tabel 1 Sistem Monitoring dan Indikator Performansi

\begin{tabular}{cc}
\hline Sistem Monitoring & Indikator Performansi \\
\hline$<40$ & Poor \\
$40-50$ & Marginal \\
$50-70$ & Average \\
$70-90$ & Good \\
$>90$ & Exellent \\
\hline
\end{tabular}

(Sumber : Volby, 2000.)

\subsubsection{Analytical Hierarchy Process (AHP)}

AHP merupakan suatu model pendukung keputusan yang dikembangkan oleh Thomas L. Saaty pada tahun 1970. Analytical Hierarchy Process merupakan teknik untuk mmbantu menyelesaikan masalah yang bersifat kompleks dengan cara mendekompisisikan masalah tersebut menjadi level - level hirarki (Sharma et al., 2008).

\subsubsection{Perbandingan Berpasangan}

Perbandingan dilakukan berdasarkan kebijakan pembuat keputusan dengan menilai tingkat kepentingan satu elemen terhadap elemen lainnya. Proses perbandingan berpasangan, dimulai dari level hirarki paling atas yang ditujukan untuk memilih kriteria, misalnya A, kemudian diambil elemen yang akan dibandingkan, misal A1, A2, dan A3.Untuk menentukan nilai kepentingan relatif antar elemen digunakan skala bilangan dari 1 sampai 9 (Skala Saaty). Untuk dapat menentukan data yang diambil konsisten maka dilakukan uji konsistensi.Penghitungan konsistensi logis adalah menghitung penyimpangan dari konsistensi, nilai dari penyimpangan ini disebut indeks konsistensi. Data dikatakan konsisten apabila $(\mathrm{CR}) \leq 0.1$. Nilai indeks random dapat dilihat pada tabel di bawah ini :

Tabel 2 Nilai Indeks Random

\begin{tabular}{|c|c|c|c|c|c|c|c|c|c|c|c|}
\hline & a. 1 & b. 2 & c. 3 & d.4 & e. 5 & f. 6 & g.7 & h. 8 & i. 9 & j. 10 & 11 \\
\hline RI & k.0.00 & 1. 0.00 & m. 0.58 & n.0.90 & 0.1 .12 & p.1.24 & q.1.32 & r. 1.41 & s. 1.45 & t. 1.49 & 1.51 \\
\hline
\end{tabular}

\subsubsection{Geometric Mean}

Geometric mean ini dapat digunakan untuk menghitung rata-rata penilaian perbandingan berpasangan dengan tetap memperhatikan ciri-ciri reciprocality dari metrik tadi.Rata-rata geometrik menyatakan bahwa jika terdapat $n$ partisipan yang melakukan perbandingan berpasangan, maka terdapat $\mathrm{n}$ jawaban atau nilai numerik untuk setiap pasangan. Untuk mendapatkan masing-masing nilai harus dikalikan satu sama lain kemudian hasil perkalian itu harus dipangkatkan $1 / n$ (Hasyim, 2013).

\section{METODOLOGI PENELITIAN}

\subsection{Fokus Kajian dan Tempat}

Fokus kajian dalam penelitian ini ialah pengukuran atribut - atribut SCOR untuk mengukur performansi rantai pasok industri batik tipe produksi Make - To - Stock dengan model SCOR 11.0 dan pembobotan AHP. Proses rantai pasok yang terdapat pada model SCOR yakni Plan, Source, Make, Delivery, Return, dan Enable. Atribut SCOR yakni Reliability, Responsiveness, Agility, Cost dan Asset Managament. Masing - masing atribut tersebut dihitung berat masing - masing 
bobotnya dengan menggunakan AHP. Objek penelitian yaitu industri batik tipe produksi Make - To - Stock dengan studi kasus Batik Gunawan Setiawan yang beralamat di Kampung Wisata Batik Kauman, Jalan Cakra No.21, Surakarta, Jawa Tengah 57112, Indonesia.

\subsection{Kebaharuan Kajian}

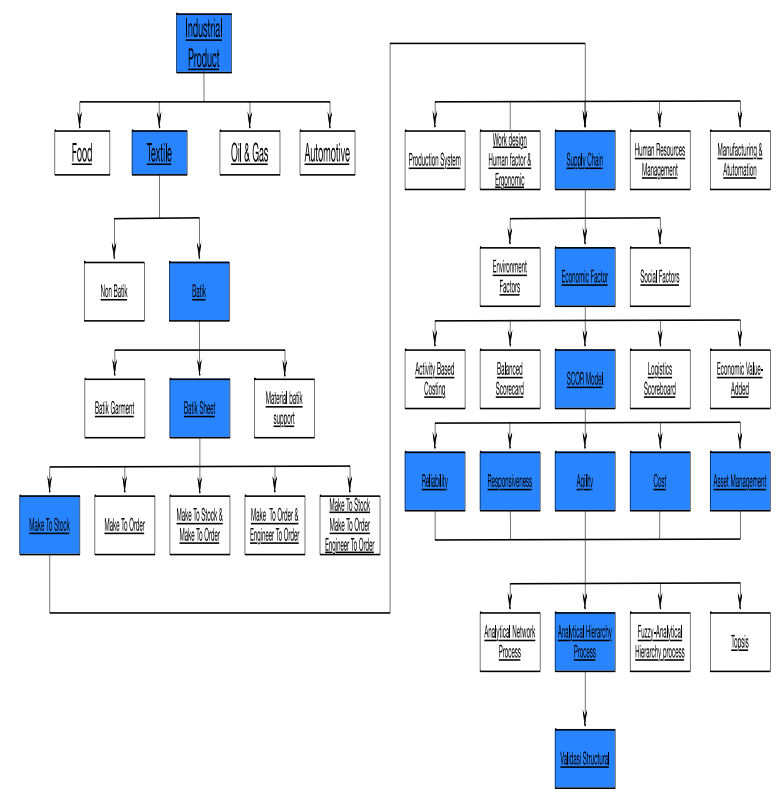

Gambar. 2 K-Chart Penelitian.

Penelitian ini mencoba untuk mengembangkan model konseptual dengan melakukan pengukuran performansi supply chain pada industri produk textile yakni Industri Batik studi kasus pada Batik Gunawan Setiawan di Surakarta dengan tipe produksi Make-To-Stock. Pengukuran Supply Chain fokus pada faktor ekonomi menggunakan model SCOR 11.0 dengan mengukur tingkat kepentingan atribut-atribut dalam proses SCOR yaitu Reliability, Resposiveness, Agility, Cost dan Asset Management. Metode AHP digunakan untuk melakukan pembobotan pada atribut - atribut Supply Chain. Masing - masing atribut akan diukur berat konstribusinya menggunakan AHP sehingga dapat mengetahui tingkat kepentingan antar atribut tersebut.Hasil pengukuran masing - masing atribut dikalikan dengan berat bobot kontribusinya sehingga didapatkan hasil performansi rantai pasok dari perusahaan. Penelitian ini termasuk dalam ruang lingkung Supply Chain Management yang memiliki state of the art.

\subsection{Kebutuhan Data}

\subsubsection{Data Primer}

Data primer adalah data yang didapatkan oleh peneliti secara langsung melalui sumbernya. Dapat berupa observasi langsung, kuesioner, dan wawancara langsung. Adapun data primer yang dibutuhkan dalam penelitian ini adalah sebagai berikut :

\section{a. Data Reliability}

Data Reliability yang dimaksud disini adalah data pemenuhan order atau kebutuhan sempurna yang dilakukan oleh perusahaan.Data tersebut diperoleh langsung dari pengamatan, wawancara dan data historis perusahaan. Data Reliability terkait dengan pemenuhan order sempurna yang dibutuhkan adalah meliputi data permintaan,data peramalan,ketepatan waktu pengiriman, ketepatan waktu penerimaan order, verifikasi jumlah dan kualitas produk dari Supplier, danverifikasi jumlah dan kualitas produk dari Customers.

b. Data Responsiveness

Data Responsiveness yang dimaksud disini adalah data waktu siklus perusahaan dalam memenuhi kebutuhan dari konsumen.Data tersebut diperoleh langsung dari pengamatan langsung dan wawancara pada perusahaan.Data Responsiveness terkait dengan waktu siklus pemenuhan order sempurna yang dibutuhkan meliputi waktu siklus pengadaan, waktu siklus produksi, waktu siklus pengiriman, dan waktu siklus pengembalian.

c. Data Agility

Data Agility ialah data pertambahan waktu yang dibutuhkan perusahaan dalam menyelesaikan order atau 
permintaan pasar ketika order naik sebesar 20\%.Data tersebut diperoleh langsung dari kalkulasi dan wawancara terhadap manager perusahaan.Data Agility terkait dengan pertambahan waktu siklus pemenuhan order sempurna jika order bertambah menjadi $20 \%$ tidak didapatkan secara terperinci.

d. Data Cost

Data Cost yang dimaksud disini adalah data total pengeluaran yang dikeluarkan perusahaan setiap bulannya yang meliputi biaya pembelian bahan baku, biaya produksi, gaji pekerja, penjualan, pengiriman, dan biaya pengembalian.

e. Data Asset Management

Data AssetManagement disini terkait dengan Cash to Cash Cycle Time yakni waktu yang dibutuhkan perusahaan dalam perputaran bisnisnya. Data yang mendukung adalah hari penjualan tertunda, data hari suplai sediaan, dan data hari hutang tertunggak.Data yang secara terperinci tidak didapatkan dari perusahaan, tetapi data ini didapatkan dari atribut - atribut sebelumnya.

Data primer lainnya yaitu nilai perbandingan berpasangan untuk masingmasing atribut rantai pasok yang meliputi Reliability, Responsiveness, Agility, Cost, dan Asset management melalui kuesioner.

\subsubsection{Data Sekunder}

Data sekunder merupakan data yang diperoleh secara tidak langsung sebagai penunjang dalam penyusunan penelitian ini.Data sekunder didapat melalui studi literatur.

\subsection{Metode Pengumpulan Data}

Data - data yang diambil merupakan penunjang dalam penyusunan penelitian ini. Dalam proses pengumpulan data, maka perlu diketahui jenis dan metode yang digunakan. Adapun tata cara pengambilan data yang dilakukan dalam penelitian ini berdasarkan jenis data yang dibutuhkan yaitu meliputi :

\section{Primer (Langsung)}

Data primer merupakan data yang diperoleh dari pengamatan secara langsung pada objek yang akan diteliti atau dikaji. Data primer yang dilakukan dalam penelitian ini melalui Observasi Langsung, Wawancara, dan Kuesioner dengan skala perbandingan :

a. Observasi langsung, ini dilakukan dengan mengumpulkan data secara langsung melakukan observasi di lapangan dengan cara melakukan pengamatan dari segi jumlah dan waktu yang dibutuhkan untuk setiap aktivitasaktivitas dalam proses bisnis perusahaan mulai dari proses perencanaan, pengadaan sumber daya, waktu siklus pembuatan produk, pengiriman barang, pengembalian dan pengelolaan.

b. Wawancara, ini dilakukan dengan cara tanya jawab atau bertatap muka langsung dengan sumber terpercaya untuk mendapatkan data.

c. Kuesioner, ini dilakukan dengan cara menyebarkan kuesioner kepada 3 responden yang diberikan kepada expert, meliputi pengambil keputusan (Manager perusahaan) dan pakar - pakar yang mengetahui batik secara mendalam. Kuesioner disusun dalam bentuk kuesioner perbandingan berpasangan dengan memberikan skala untuk perbandingan masing - masing atribut dalam SCOR.

\section{Sekunder (Tidak langsung)}

Data sekunder merupakan data yang diperoleh secara tidak langsung sebagai penunjang dalam penyusunan penelitian ini. Data sekunder didapat melalui metode kajian pustaka :

a. Kajian Pustaka dilakukan dengan mendapatkan teori-teori yang akan menunjang peneliti didalam melakukan penelitian ini.

b. Mencari data historis yang biasanya telah disediakan oleh perusahaan. 


\section{HASIL DAN PEMBAHASAN}

Pengukuran performansi rantai pasok pada Batik Gunawan Setiawan dengan menggunakan model SCOR 11.0 mendapatkan hasil performansi rantai pasok perusahaan berdasarkan nilai dari masingmasing atribut yang telah diukur menggunakan model SCOR 11.0 untuk masing-masing jenis produk yang dihasilkan.

\subsection{Pengukuran SCOR 11.0}

Tabel.3 Hasil Perhitungan SCOR 11.0

\begin{tabular}{|c|c|c|c|c|}
\hline \multirow[b]{2}{*}{ No } & \multirow[b]{2}{*}{ Atribut } & \multicolumn{3}{|c|}{ SCOR } \\
\hline & & $\begin{array}{l}\text { Batik } \\
\text { Tulis }\end{array}$ & $\begin{array}{c}\text { Batik } \\
\text { Cap }\end{array}$ & $\begin{array}{c}\text { Batik } \\
\text { Kombi } \\
\text { nasi }\end{array}$ \\
\hline 1 & Reliability & $98.17 \%$ & $97.65 \%$ & $97.60 \%$ \\
\hline 2 & $\begin{array}{l}\text { Responsi- } \\
\text { veness }\end{array}$ & $\begin{array}{c}64.40 \\
\text { hari }\end{array}$ & $\begin{array}{c}40.78 \\
\text { hari }\end{array}$ & $\begin{array}{c}60.19 \\
\text { hari }\end{array}$ \\
\hline 3 & Agility & $\begin{array}{c}14.39 \\
\text { hari }\end{array}$ & $\begin{array}{c}14.70 \\
\text { hari }\end{array}$ & $\begin{array}{c}17.61 \\
\text { hari }\end{array}$ \\
\hline 4 & Cost & $\begin{array}{l}\text { Rp.185, } \\
173,537\end{array}$ & $\begin{array}{c}\text { Rp. } 273 \\
, 292,49 \\
1\end{array}$ & $\begin{array}{c}\text { Rp. } 271 \\
, 219,75 \\
0\end{array}$ \\
\hline 5 & $\begin{array}{c}\text { Asset } \\
\text { Manage- } \\
\text { ment }\end{array}$ & $\begin{array}{c}20.15 \\
\text { hari }\end{array}$ & $\begin{array}{c}18.04 \\
\text { hari }\end{array}$ & $\begin{array}{c}21.17 \\
\text { hari }\end{array}$ \\
\hline
\end{tabular}

Berdasarkan pada tabel di atas dapat diketahui hasil perhitungan SCOR untuk masing-masing jenis batik yaitu berturutturut atribut Reliability yaitu Batik Tulis $98.17 \%$, Batik Cap $97.65 \%$ dan Batik Kombinasi $97.60 \%$. Hasil perhitungan SCOR untuk atribut Responsiveness berturut - turut untuk setiap jenis batik yaitu Batik Tulis 64.40 hari, Batik Cap 40.78 hari dan Batik Kombinasi 60.19 hari. Lalu hasil perhitungan SCOR untuk atribut Agility yaitu Batik Tulis 14.39 hari, Batik Cap 14.70 dan Batik Kombinasi 17.61 hari. Hasil perhitungan SCOR untuk atribut Cost yaitu Rp. 185,173,537.-, Batik Cap Rp. 273,292,491.dan Batik Kombinasi Rp.271,219,750.-. Dan hasil perhitungan SCOR untuk atribut Asset management yaitu Batik Tulis 20.15 hari, Batik Cap 18.04 hari dan 21.17 hari.

\subsection{Pembobotan AHP}

Tabel 4 Bobot Prioritas

\begin{tabular}{|c|c|c|c|c|c|c|c|}
\hline Atribut & $\mathbf{R L}$ & RS & AG & $\mathrm{CO}$ & AM & $\begin{array}{c}\text { Tota } \\
1\end{array}$ & Bobo \\
\hline RL & 0.04 & 0.004 & 0.19 & 0.01 & 0.15 & 0.39 & 0.079 \\
\hline RS & 0.16 & 0.14 & 0.40 & 0.02 & 0.26 & 0.97 & 0.194 \\
\hline AG & $\begin{array}{c}0.000 \\
4\end{array}$ & 0.001 & 0.02 & $\begin{array}{c}0.00 \\
4\end{array}$ & 0.15 & 0.17 & 0.035 \\
\hline $\mathrm{CO}$ & 0.80 & 0.85 & 0.40 & 0.97 & 0.43 & 3.44 & 0.689 \\
\hline $\mathbf{A M}$ & 0.00 & 0.00 & 0.00 & 0.00 & 0.01 & 0.02 & 0.003 \\
\hline Jumlah & 1.00 & 1.00 & 1.00 & 1.00 & 1.00 & 5.00 & 1.000 \\
\hline
\end{tabular}

Besar bobot untuk masing - masing atribut SCOR yaitu atribut Reliability 0.079, Responsiveness 0.194, Agility 0.035, Cost 0.689, dan Asset Management 0.003, sehingga dapat diketahui bahwa atribut yang paling berpengaruh yaitu cost dengan bobot sebesar 0.689. Dikarenakan jumlah data yang digunakan yaitu 5 sehingga tabel IR-nya yaitu 1.15.Dan dilakukan perhitungan konsistensi rasio dengan hasil yaitu untuk konsistensi rasio sebesar 0.02.Uji konsistensi dikatakan benar atau konsisten jika rasio konsistensi $(\mathrm{CR}) \leq 0.1$, sehinga hasil perhitungan konsistensi rasio dikatakan benar atau data yang digunakan konsisten (lulus uji konsistensi) yaitu CR $(0.002) \leq 0.1$

\subsection{Pembobotan SCOR 11.0 dengan AHP}

Berdasarkan pada hasil perhitungan SCOR untung masing-masing jenis batik dan pembobotan untuk masing-masing atribut SCOR 11.0 menggunakan AHP maka dapat dilakukan perhitungan hasil SCOR 11.0 dengan pembobotan AHP yaitu sebagai berikut:

Tabel 5 Hasil Perhitungan SCOR Akhir Batik Tulis

\begin{tabular}{|c|c|c|c|c|c|c|}
\hline Atribut & $\begin{array}{c}\text { Batik } \\
\text { tulis }\end{array}$ & Target & Hasil & $\begin{array}{l}\text { Bo- } \\
\text { bot }\end{array}$ & $\begin{array}{c}\text { Hasil } x \\
\text { Bobot }\end{array}$ & $\begin{array}{c}\text { SCO } \\
\text { R } \\
(\%) \\
\end{array}$ \\
\hline $\begin{array}{c}\text { Reliabili } \\
\text { ty }\end{array}$ & $98.17 \%$ & $100 \%$ & $98 \%$ & 0.079 & $\begin{array}{c}7.7 \\
\%\end{array}$ & \multirow{5}{*}{$\begin{array}{l}81 \\
10 \\
\%\end{array}$} \\
\hline $\begin{array}{c}\text { Respons } \\
\text { iveness }\end{array}$ & $\begin{array}{c}64.40 \\
\text { hari }\end{array}$ & 60 hari & $93 \%$ & 0.194 & $\begin{array}{l}18 . \\
0 \%\end{array}$ & \\
\hline Agility & $\begin{array}{c}14.39 \\
\text { hari }\end{array}$ & & $69 \%$ & 0.035 & $\begin{array}{l}2.4 \\
1 \%\end{array}$ & \\
\hline Cost & $\begin{array}{c}\mathrm{Rp} \\
185,173 \text {, } \\
537\end{array}$ & $\begin{array}{c}\mathrm{Rp} \\
150,000 \\
, 000\end{array}$ & $77 \%$ & 0.689 & $\begin{array}{l}52 . \\
72 \\
\%\end{array}$ & \\
\hline $\begin{array}{c}\text { Asset } \\
\text { manage } \\
\text { ment }\end{array}$ & $\begin{array}{c}20.15 \\
\text { hari }\end{array}$ & 16 hari & $74 \%$ & 0.003 & $\begin{array}{l}0.2 \\
6 \%\end{array}$ & \\
\hline & \multicolumn{3}{|c|}{ Total } & \multicolumn{3}{|c|}{$\begin{array}{c}81.10 \\
\%\end{array}$} \\
\hline
\end{tabular}


Dari tabel di atas dapat diketahui nilai untuk masing - masing atributbatik tulis setelah dikalikan dengan target perusahaan yaitu Reliability dan Responsiveness sebesar 98\% dan 93\%. Nilai tersebut menunjukkan bahwa atribut Reliability dan Responsiveness termasuk dalam kategori sangat baik (Exellent). Sedangkan nilai untuk atribut Agilitiy, Cost, dan Asset Management yaitu berturut-turut setelah dikalikan dengan target perusahaan sebesar 69\%, 77\%, dan $74 \%$.Hasil tersebut menunjukkan nilai performansi atribut Agility termasuk dalam kategorisedang (Average). Sedangkan atribut Cost dan Asset Management termasuk kategori baik (Good). Hasil akhir SCOR setelah dikalikan dengan bobot masing masing atribut untuk batik tulis, didapatkan hasil SCOR yaitu sebesar 81.10\%. Hasil tersebut dapat dianalisa untuk tingkat performansi rantai pasok batik tulis Gunawan Setiawan yaitu baik (Good) dari total nilai $100 \%$.

Tabel 6 Hasil Perhitungan SCOR Akhir Batik

\begin{tabular}{|c|c|c|c|c|c|c|}
\hline \multirow[b]{2}{*}{ Atribut } & \multirow[b]{2}{*}{$\begin{array}{l}\text { Batik } \\
\text { Cap }\end{array}$} & \multirow[b]{2}{*}{ Target } & \multirow[b]{2}{*}{ Hasil } & \multicolumn{3}{|c|}{ Hasi } \\
\hline & & & & $\begin{array}{c}\text { Bob } \\
\text { ot }\end{array}$ & $\begin{array}{c}1 \mathrm{x} \\
\text { Bob } \\
\text { ot }\end{array}$ & $\begin{array}{c}\text { SCOR } \\
(\%)\end{array}$ \\
\hline $\begin{array}{c}\text { Reliabili } \\
\text { ty }\end{array}$ & $\begin{array}{c}97.65 \\
\%\end{array}$ & $100 \%$ & $98 \%$ & $\begin{array}{c}0.07 \\
9\end{array}$ & $8 \%$ & \\
\hline $\begin{array}{c}\text { Respons } \\
\text { iveness }\end{array}$ & $\begin{array}{c}40.78 \\
\text { hari }\end{array}$ & 30 hari & $64 \%$ & $\begin{array}{c}0.19 \\
4\end{array}$ & $12 \%$ & \\
\hline Agility & $\begin{array}{c}14.70 \\
\text { hari }\end{array}$ & 11 hari & $66 \%$ & $\begin{array}{c}0.03 \\
5\end{array}$ & $2 \%$ & $6635 \%$ \\
\hline Cost & $\begin{array}{c}\mathrm{Rp} \\
273,29 \\
2,491\end{array}$ & $\begin{array}{c}\mathrm{Rp} \\
200,000, \\
000\end{array}$ & $63 \%$ & $\begin{array}{c}0.68 \\
9\end{array}$ & $44 \%$ & $00.35 \%$ \\
\hline \multirow[t]{2}{*}{$\begin{array}{c}\text { Asset } \\
\text { manage } \\
\text { ment }\end{array}$} & $\begin{array}{c}18.04 \\
\text { hari }\end{array}$ & 14 hari & $71 \%$ & $\begin{array}{c}0.00 \\
3\end{array}$ & $\begin{array}{c}0.25 \\
\%\end{array}$ & \\
\hline & & Total & & & $\begin{array}{c}66.3 \\
5 \%\end{array}$ & \\
\hline
\end{tabular}

Dari tabel di atas dapat diketahui nilai untuk masing - masing atribut batik cap setelah dikalikan dengan target perusahaan yaitu Reliability sebesar $98 \%$. Nilai tersebut menunjukkan bahwa atribut Reliability termasuk dalam kategori sangat baik (Exellent). Sedangkan nilai untuk atribut Responsiveness, Agilitiy, danCost yaitu berturut - turut sebesar 64\%, 66\%, dan $63 \%$. Hasil tersebut menunjukkan nilai performansi atribut Responsiveness, Agility, dan Cost termasuk dalam kategori sedang (Average). Sedangkan atribut Asset Management mendapatkan hasil sebesar $71 \%$ dan termasuk kategori baik (Good). Hasil akhir SCOR setelah dikalikan dengan bobot masing - masing atribut untuk batik cap dan didapatkan hasil SCOR yaitu sebesar $66.35 \%$. Hasil tersebut dapat dianalisa untuk tingkat performansi rantai pasok batik cap Gunawan Setiawan yaitu sedang (Average) dari total nilai $100 \%$.

Tabel 7 Hasil Perhitungan SCOR Akhir Batik Kombinasi

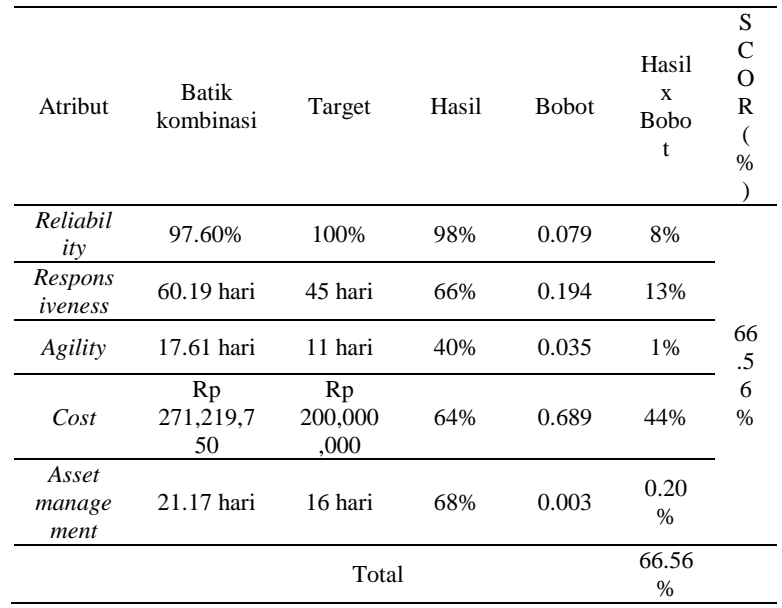

Dari tabel di atas dapat diketahui nilai untuk masing - masing atribut batik kombinasi setelah dikalikan dengan target perusahaan yaitu Reliability sebesar $98 \%$. Nilai tersebut menunjukkan bahwa atribut Reliability termasuk dalam kategori sangat baik (Exellent). Nilai untuk atribut Responsiveness, Cost, dan Asset Management berturut - turut sebesar 66\%, 64\%, dan 68\% dan termasuk dalam kategori sedang (Average). Sedangkan nilai untuk atribut Agilitiy yaitu sebesar $40 \%$. Hasil tersebut menunjukkan nilai performansi atribut Agility termasuk dalam kategori rendah (Marginal). Hasil akhir SCOR setelah dikalikan dengan bobot masing - masing atribut untuk batik kombinasi dan didapatkan hasil SCOR yaitu sebesar $66.56 \%$. Hasil tersebut dapat dianalisa untuk tingkat performansi rantai pasok batik cap Gunawan Setiawan yaitu sedang (Average) dari total nilai $100 \%$. 
Tabel 8 Hasil Perhitungan SCOR Batik Gunawan Setiawan

\begin{tabular}{cccc}
\hline Jenis batik & SCOR & Bobot & $\begin{array}{c}\text { SCOR } \\
\text { Keseluruhan }\end{array}$ \\
\hline Batik Tulis & $81.10 \%$ & $16 \%$ & \\
Batik Cap & $66.35 \%$ & $45 \%$ & $68.79 \%$ \\
Batik kombinasi & $66.56 \%$ & $39 \%$ & \\
\hline
\end{tabular}

Tabel di atas merupakan hasil perhitungan nilai performansi rantai pasok Batik Gunawan Setiawan setelah dikalikan dari hasil SCOR masing - masing batik dengan bobot proporsi volume produksi dan didapatkan hasil yaitu $68.79 \%$, hasil ini menunjukkan bahwa nilai performansi rantai pasok Batik Gunawan Setiawan yaitu termasuk kategori sedang (Average), hal ini disebabkan oleh berbagai faktor yaitu kemampuan Responsiveness atau kecepatan perusahaan dalam melakukan pemenuhan kebutuhan pasar, rata - rata sedang dari target perusahaan sehingga waktu dalam pemenuhan kebutuhan belum memenuhi target. Selain itu daya tanggap perusahaan dalam menanggapi perubahaan permintaan pasar dan biaya yang dikeluarkan perusahaan untuk memproduksi barang masih sangat tinggi dan rata - rata belum mendekati target perusahaan sehingga berdampak juga pada lama waktu perputaran asset perusahaan. maka diperlukan perbaikan lebih lanjut agar dapat meningkatkan performansi ranti pasok pada Batik Gunawan Setiawan.

\section{KESIMPULAN DAN SARAN}

\subsection{Kesimpulan}

Dari hasil pengukuran untuk masingmasing atribut, maka dapat disimpulkan bahwa rata - rata dari hasil pengukuran termasuk dalam kategori sedang (Average) sehingga masih diperlukan perbaikan lebih lanjut. Besar bobot untuk masing - masing atribut SCOR yang berhubungan dengan performansi rantai pasok industri batik yaitu atribut Reliability 0.079, Responsivenes 0.194, Agility 0.035, Cost 0.689, dan Asset Management 0.003. Dari hasil pembobotan tersebut maka dapat disimpulkan bahwa atribut yang paling berpengaruh yaitu Cost dengan bobot sebesar 0.689. Hasil pengukuran performansi rantai pasok industri batik Gunawan Setiawan yaitu sebesar $68.79 \%$ ini termasuk dalam indicator performansi sedang(Average) sehingga diperlukan perbaikan lebih lanjut untuk meningkatkan performansi rantai pasok Batik Gunawan Setiawan secara keseluruhan.

\subsection{Saran}

Melihat dari hasil perhitungan bobot yang paling berpengaruh untuk masing masing atribut rantai pasok yaitu Cost dan pengukuran masing - masing atribut maka dapat diberikan rekomendasi. Rekomendasi yang dirumuskan sehingga dapat meningkatkan performansi rantai pasok pada Batik Gunawan Setiawan yaitu dengan cara menghilangkan ataupun mengurangi aktivitas - aktivitas yang tidak menambah nilai atau non value addedse pertimenghilangkan proses Corek (pemolaan) pada kain yang dilakukan pada proses batik tulis karena proses ini dianggap sebagai Innapriorate processing. Dimana proses pencorekan berfungsi untuk memberikan pola pada kain sebelum dilakukan proses Chanting / batik pada kain. Proses ini dapat dihilangkan karena pengrajin Canthing langsung dapat menorehkan Canthing pada kain untuk batik tulis tanpa harus menunggu kain untuk dipola. Selain itu mengurangi waktu tunggu dari proses pewarnaan menuju proses pengeringan Waste waiting, proses pewarnaan langsung dikeringkan tanpa ditumpuk terlebih dahulu. Melakukan negosiasi dan pemilihan Supplier yang tepat untuk meningkatkan performansi pengadaan bahan baku baik dari segi kecepatan maupun kualitas, sehingga dapat memasok aliran bahan baku berdasarkan dengan kebutuhan dari perusahaan.

Saran untuk penelitian lebih lanjut yaitu diperlukannya penelitian dengan metode perbaikan statistical untuk meningkatkan performansi rantai pasok sehingga dapat diketahui perubahan dari tingkat perbaikan 
yang dilakukan.Perlunya penelitian lanjut tentang hubungan antara masing - masing atribut, sehingga apabila dilakukan perbaikan terhadap salah satu atribut maka dapat diketahui sejauhmana pengaruh perubahan terhadap atribut yang lain.

\section{DAFTAR PUSTAKA}

Cooper, M., Lambert, D. \& Pagh, J. Supply chain management : more than a new name for logistics. International Journal of Logistics Management. 8(1), 1-14, 1997.

De Garmo E. P., Back J. T. \& Kohser A. R. Materials and Process in Manufacturing. $8^{\text {th }} \quad$ Internatioan Edition.Prentice Hall. Upper Saddle River. N. J, 1997.

Dedi, Deden S. Sejarah Batik Indonesia. PT. Sarana Panca Karya Nusa : Bandung, 2009.

Djumena, Dian S. Batik dan Mitra (Batik and Its Kind).Djambatan : Jakarta, 1990.

Georgise, F. B. \& Thoben, K.D. Asseing the Existing Performance Measures \& Measurement System in Developing Countries: An Ethiopian Study, Global Journal of Researches in Engineering Industrial Engineering. 2013.

Hanna, M.D. \& W.R. Newman. Operations Management Integrated Approach. Prentice Hall, Inc., New Jersey. 2001.

Hasyim, H. Modul Perkuliahan : Pengambilan Keputusan Manajerial. Fakultas Ekonomi dan Bisnis, Universitas Mercu Buana, Jakarta. 2013.

Heizer, J. \& Render, B. Manajemen Operasi (Terjemahan Edisi Tujuh). Salemba Empat, Jakarta. 2005.

Huan, Samuel, H., Sheoran, Sunil, K. \& Ge Wang. A Review and Anaysis of SC
Operation Reference (SCOR) model. Supply Chain Management: An International Journal, Vol. 9, No. 1, 23-29. 2004.

Lockamy, Archie \& Cormack, Kevin Mc. Linking SCOR Planning Practice to Supply Chain Performance An Exploratory Study. International Journal of Operation and Production Management. Doi: 10.1108/01443570410569010, 2004.

Paul, John. Panduan Penerapan Transformasi Rantai Suplai dengan Model SCOR. PPM. Jakarta. 2014.

Persson, F. SCOR template-A simulation based dynamic supply chain analysis tool. International Journal of Production Economics, 131(1), 288294.

http://doi.org/10.1016/j.ijpe.2010.09.02 9. 2011.

Pujawan, I Nyoman \& ER., Mahendrawati. Supply Chain Management. Penerbit Gunawidya : Surabaya, 2010.

Pujawan, I Nyoman. Supply Chain Management, Guna Widya, Surabaya. 2005.

Russell, R.S. \& Taylor, B.W. Operations Management. Prentice Hall, New Jersey. 2003.

Sarmini. Pakaian Batik : Kulturisasi Negara dan Politik Identitas. Jurnal Sejarah dan Budaya, Vol. 4, No. 8, Desember 2009.

Sharma, Mithun, J., Moon, Ilkyeong \& Bae, Hyerim. Analytical Hierarchy Process to Acces and Optimize Distribution Network. Applied mathematics and Computation, 202, 256-265. 2008.

Sumintarsih. 2009. Pelestarian Batik dan Ekonomi Kreatif.Jurnal Sejarah dan Budaya, Vol. 4, No. 8, Desember 2009. 
Supply Chain Council Team. Supply Chain Operations Reference ModelRevision 11.0. SSC, Inc. ISBN 0-615-20259-4, 2012 .

Volby, H. Performance Measurement and Improvement Supply Chain. Thienekers. 2000.

Xia, Laura Xu Xiao, Ma., Bin \& LIM, Roland. AHP Based Supply Chain Performance Measurement System. IEEE: $\quad 1-4224-0826-1 \quad / 07 / \$ 20.00$. 2007. 2007. 